\title{
Amsterdam Smart City (ASC): fishing village to sustainable city
}

\author{
M. Somayya \& R. Ramaswamy \\ IT Applications Group, National Institute of Industrial Engineering \\ (NITIE), India
}

\begin{abstract}
'Smart City' is the new buzzword creating ripples in the urban well. This new urban paradigm shift is all set to usher sustainability, content, and joy to a hitherto troubled and challenge-ridden urban life. The main objective of building Smart Cities is to provide Quality of Life (QoL), economic development and ecological balance. These cities are the nodal points for civic services like safety, health, sanitation, power supply, potable water, houses and city administration in a technological way. Though the concept of 'Smart Cities' can be traced back to 1992, its first name was "Digital Cities". This got transformed into several other names denoting sustainability, such as Wired Cities, Connected Cities, Internet Cities, I Cities, Cyber Cities, Ubiquitous Cities, Intelligent Cities, Sustainable Cities, and finally, Smart Cities. Considering the high significance of planning environmentally sustainable, easily manoeuvrable and economically feasible urban settlements, this research article provides an overview of the fundamental concepts of a sustainable city. This manuscript takes up Amsterdam as a case study, explaining how the old fishing village, Amsterdam has transformed into the present day Sustainable Smart City. This article is based on an exploratory study, in line with the case study methodology. Data was collected from online, including blogs, white papers, research reports, notes and articles, while the scripting was done through thematic narration. The outcome discloses that the city is deploying an enormous number of Internet of Things (IoT) technologies for civic services available in $24 \times 7$. With less pollution, less waste and number of green buildings, these cities are contributing largely towards sustainability. New urban solutions are developing with the help of Almere Smart Society, 3D Print Canal House, City-zen-Sustainable District Heating, and Vehicle2Grid projects, to name a few. Keywords: Smart Amsterdam, sustainable cities, renewable energy, $3 D$ printing.
\end{abstract}




\section{Introduction}

Human life started millions of years ago, along with nature's other creations. However, the human life has always been considered separately from other flora and faunas, due to the uniquely superior knowledge, intelligence, wisdom and mental perspicacity of this species. Unfortunately, with this enhanced mental prowess, human beings undertook an almost mindless extraction of natural resources for their short-term progress. As a result, over a period of time, human development has reached a stage where it is threatening the very existence of an ecosystem. The rapid advancement in the industrialisation, the manufacturing, the globalisation, the technological development and the fast urbanisation are some of the sectors that are threatening the environment. The natural complex system and its intra and inter connections are not balanced anymore, leading to various natural calamities. The previous works denote that many complex systems in nature and society can be described in terms of network, capturing the intricate web of connections among the units they are made of $[1,2]$. Hence, deforestation, much industry plantation, increasing vehicle usage, heavy fuel energy consumption, the material movement for better quality housing and global business trade are some of the antecedents for increasing or decreasing connectivity forces of natural complex systems. Vitally, the basic life cycle of $\mathrm{O}_{2}$ and $\mathrm{CO}_{2}$ plays an important role in the complete life cycle of the system. Fluctuation in the $\mathrm{O}_{2}$ and $\mathrm{CO}_{2}$ levels leads to global warming. Some of the recent paradigms are (1) massive earthquake devastation in Nepal on April 25, 2015, killing more than 8,800 people; (2) torrential rains in November 2015, which caused severe flooding in southern India (Chennai); (3) Below-average rainfall over several planting seasons has caused crop failures and death of large numbers of livestock in Ethiopia, paralyzing the livelihoods of many farmers.

In this light, human beings should re-think before exploiting mindlessly natural resources for their development and attempt to usher Quality of Life activities. One should keep in mind the importance of the environment. It is the need of the hour that every human being designs more efficient products and solutions for improving life without disturbing the earth's already fragile ecosystem. It is the collective responsibility of the citizens to take care of the mother earth. One way of protecting the environment is by reducing usage of fossil fuels and increasing the use of renewable resources for lighting human life. Renewable energy resource is a numerate and quantitative text covering the full range of renewable energy technologies and their implementation worldwide. Energy can be supplied from various renewable sources, such as biofuels, solar heat, photovoltaics, wind, hydro, wave and tidal energy [3]. It is expected that by the year 2020, there will be 50 billion smart devices connected to the Future Internet (FI) for better life. These large numbers of electronic devices require an abundant power. Supplying energy round the clock for these devices is very difficult through the traditional electricity generation method. Hence, energy production from renewable natural resources such as solar heat, wind and geothermal sources should be considered for replenishing the need for energy, thus leading to sustainable human life. 


\section{Sustainable smart cities}

"Sustainability" is the buzzword in every corner of the globe. Even though the term 'sustainability' emerged approximately three decades ago, it failed to grab much understanding and attention then. Nowadays, plenty of discussions are taking place on this topic in various international conferences, workshops, symposia, and seminars. Bottles of ink had already been poured on papers, in the form of articles, reports, white papers, book chapters and books. Tons of typing has been done on "Sustainability" in the computers, laptops, mobiles and other smart devices. An enormous amount of data is stored in computers, servers, data centres and cloud on "Sustainability". Academicians, researchers, practitioners and corporate entities are trying to practice sustainable methods. Sustainability is nowadays accepted by all stakeholders as a guiding principle for both public policy-making and corporate strategies. However, the biggest challenge for most organizations is the real and substantial implementation of the sustainability concept [4]. In response to the increasing pressure coming from national and international regulations, and from society in general, corporations are gradually being pushed towards the adoption of principles of both social and environmental responsibility within their strategies, structures and management systems [5].

"Sustainability" is a concept that people have a hard time understanding. Sustainability is multi-dimensional by nature and has sprouted from interdisciplines, including environmental science, botany, zoology, sociology, history, political science, business management, information technology, electrical engineering, and urbanisation, to name a few. Though many definitions have flourished the most often-used definition of sustainable development has been proposed by the Brundtland Commission (Cerin 2006; Dernbach 1998, 2003; Stoddart 2011 [23]). "Sustainability" or "Sustainable Development" has been defined as "development that meets the needs of the present without compromising the ability of future generations to meet their own needs" [6]. This development deals with environmental, social and economic factors (1) Environmental: efficient natural resource use, carbon emission control and optimum utilisation of land, water, air and waste; (2) Social: standard of living, equal opportunity, education, and technological assistance; (3) Economic: nature profit, cost reduction, collaborative R \& D and economic development. Energy harvesting plays an important role in sustainable development, which comes under the aegis of environmental science. At present, about $85 \%$ of the world's energy consumption is supplied by fossil fuels. However, the existing fossil fuel reserves are limited, and if continued to be used at the present rate, it is estimated that coal will be exhausted in circa 250 years, oil in 60, and natural gas in roughly 80 years. Hence, sustainable energy is a dynamic harmony between the equitable availability of energy-intensive goods and services to all people and the preservation of the earth resources for future generations. Energy harvesting from alternate sources come from water, wind, tidal, biofuels, geothermal and solar energy (as shown in Figure 1). Every city has its own history, culture and identity. There is no doubt that we need to nurture, preserve and renew the urban fabric with technological advances, in keeping with the changing times. People are 
moving from rural to urban areas in the hope of finding a better job, pursuing a higher education, visiting tourist places and to enjoy higher standard of living. However, the increasing number of people migrating to city causes overcrowding of the city, thus, putting pressure on limited urban resources and infrastructure. Hence, there is a need to convert these old cities into smart cities or build new smart cities to overcome this pressure on existing cities and provide better citizen services round the clock. Cities are facing an ever-changing technological global world. Their success depends completely on their ability to adapt themselves to the changing needs of society and becoming sustainable for the future. Constitution of Sustainable Smart Cities is the only way to successfully solve these urban issues. A sustainable smart city is an innovative city that uses Information and Communication Technologies (ICT) and other means to improve Quality of Life, the efficiency of urban operation and services, and competitiveness while ensuring that it meets the needs of present and future generations with respect to economic, social and environmental aspects [7].

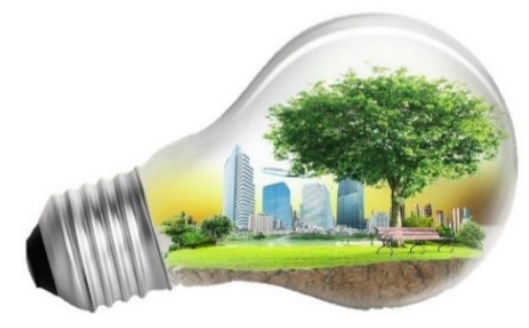

Figure 1: Sustainable energy.

Sustainable smart cities mainly concentrate on the IoT technologies' deployment within cities' axes in order to bring optimum utilisation of natural resources. Urban IoTs, in fact, are designed to support the smart city vision, which aims at exploiting the most advanced communication technologies to support added-value services for the administration of the city and the citizens [8]. Comprehensive approaches towards urban planning are advocated, which recognise the individual needs of the cities and are based on ecologically sound design practices. 'Sustainable cities' were the central concern of the meetings of the Rio conference held in Manchester in 1993-1994 [9]. For instance, smart meters' deployment will help to prevent the loss of water while transmitting from supplier to consumer. Right from the city municipality government, citizen engagement, university researchers and business houses will actively participate in building energy-efficient solutions. A large number of collaborative works will be required for innovative pollution-free solutions. New waste reduction technologies will help recycle both solid and liquid waste materials. Along with smart meters and ZigBee tools in power utilisation, water, solar, wind, geothermal and other renewable natural resources will become sources of energy. Entire data such as tourism guidance, emergency help, educational institutions', hospitality services, theme parks' directions, and government helplines via kiosks will be available in city website. Besides, ecosystem guidelines like prevention of 
smoking in public places, throwing waste in bins, sanitation-related posters will also be included. Smart Amsterdam is an energy-efficient city and the best case for sustainable development. Amsterdam is satisfying the energy needs of its citizens through its Living Lab experiments. This article discusses how and why Amsterdam is so concerned about sustainability solutions for its urban environment.

\section{Amsterdam}

"Some tourists think Amsterdam is a city of sin, but in truth, it is a city of freedom.

And in freedom, most people find sin."

$$
\text { - John Green }
$$

The city of Amsterdam is in The Netherlands; we are aware that The Netherlands is the most densely populated country in Europe and one of the most densely populated countries in the world too. Amsterdam (Holland) is the capital of The Netherlands. The city is also known as 'Venice of the North.' Amsterdam city is built on a cobweb of canals that boasts of one of the most picturesque settings in the world. Amsterdam, one of the greatest planned cities of northern Europe, has always been a well-known name in world's history. In the 17 th century, Amsterdam was the centre of the world's economy, and nowadays the city is known for its tolerant character. The beauty of this city is entirely man-made and seems to be more sensitive to basic human and environmental needs [10]. The city has always been non-conformist and progressive, encouraging a relaxed lifestyle. The Amsterdam city is planned along a gentle curve and very narrow street system, which creates a highly walkable, interesting and pleasant environment (as shown Figure 2).

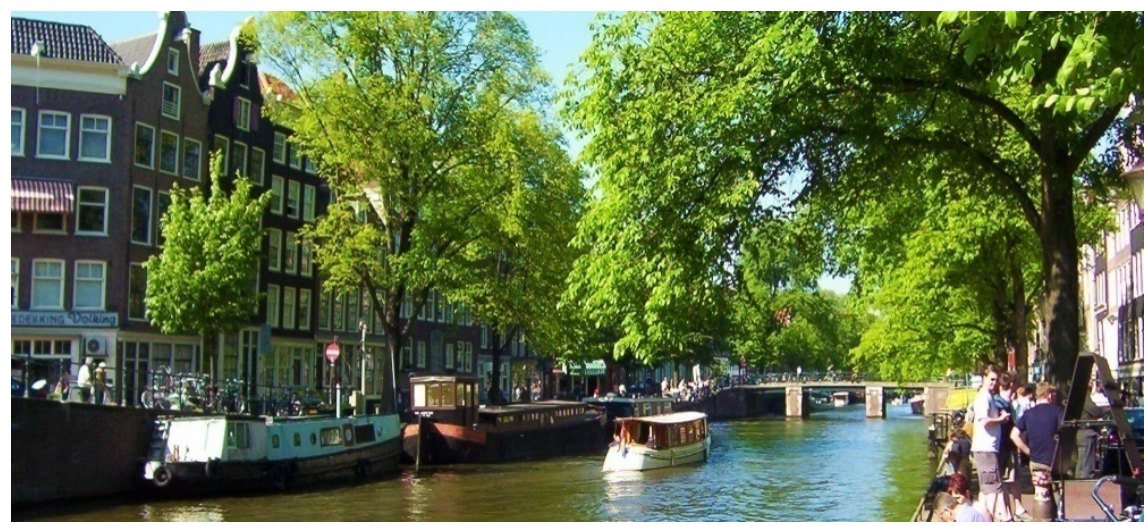

Figure 2: Good-looking environment.

What makes Amsterdam city so attractive is the 17th century historical atmosphere combined with the mentality of a modern metropolis, creating a friendly and relaxed environment. The small-scale buildings and the intimacy of the streets, canals and squares create an atmosphere that visitors find unique. 
Amsterdam is a city with a long trade tradition and a strong reputation for culture and innovation. However, the position of Amsterdam as a major national and international cultural centre has for some time been threatened by the increasing competition from other cities both within and outside The Netherlands [11]. Amsterdam city government believes in a liveable city where people can live, work, and play pleasantly. They thought that the liveable "smart city" using IoT technologies will contribute to the enhanced liveability of Amsterdam metropolitan area, promote sustainable economic growth, develop new markets and Quality of Life (QoL).

\section{Smart Amsterdam}

According to IHS Technology, San Francisco, Chicago, Los Angeles, New York, London, Amsterdam, Seoul, Hong Kong, Tokyo, and Singapore are most likely to become 'smart' before 2020. However, because of the technological advancements, economic development and efficient operations in the city, some of the other urban standard bodies have already declared Amsterdam as a "smart city". Amsterdam Smart City is also shortly known as ASC. The idea of the Amsterdam Smart City is to go from a traditional "knowledge-silo-thinking" to a holistic information community, where synergies are created through cooperation. Amsterdam Smart City stresses the importance of the smart city as an inclusive process, where the strength lies in the both quality and quantity of information shared. Amsterdam Smart City is designed in such a way that it is a walkable, cohesive and pleasant place to live in. Amsterdam is a healthy, sustainable and attractive with an innovative environment and a solid foundation for the digital future, pursuing its growth potential in order to compete globally. "Amsterdam Smart City" project was started in the year 2009 as a collaboration project between Amsterdam Innovation Motor and the grid operator Liander, in close association with the municipality of Amsterdam. Today, the project involves more than 78 partners. Amsterdam Smart City has initiated this large number of innovative projects aiming to create a more sustainable and energy-efficient city. This smart city project has provided opportunities for businesses located on IJburg and in the Districts of Nieuw-West and Zuidoost to test new products in a real-life setting; in a so-called Urban Living Lab. Some literature even speaks that the Dutch cities were chosen including Amsterdam, the capital city of The Netherlands, which is now experimenting with a large scale application of photovoltaic roof panels in one of its newly built areas [12]. Some of the smart city projects are stated below.

\subsection{Almere Smart Society}

A conglomeration of Cisco, Liander, IBM, Philips and Living PlanIT smart city planned to create a 'smart society' with the Almere Economic Development Board, through the smarter deployment of Internet of Things (IoT) technologies, people and natural resources in urban management and development. The Almere Smart Society vision involves the realization of an IoT facility, which, amongst other things, will promote the more efficient urban management, innovation and economic growth, strong social cohesion and sustainable development [13]. 


\subsection{Print canal house (3D)}

$3 \mathrm{D}$ printing is a fascinating new production technique in this technological world. It allows users to directly translate a digital file into a physical product/s. The 3D Print Canal House is an initiative of DUS architects and will be printed with the Kamermaker, a major mobile 3-dimesional printer that was developed by the architects. Kamermaker aims to print with a material that is sustainable, of biological origin, melts at a relatively low temperature, is sturdy and stable [14].

\subsection{City-zen-sustainable district heating}

Venture in sustainable district heating projects includes the optimisation of the waste and energy power station and the installation of cutting-edge daylight collectors as a new source of heat. The major benefit of these collectors is that they can even gather energy on a dreary Dutch autumn day. Waternet plans to reuse heat produced in sewers to heat buildings via a so-called waste heat recovery system. Such a waste heat recovery system helps reduce the reduction of fossil fuel resources. Heat from the sewer can be used to supplement the heat supplies of an existing geothermal heat system, using the system's existing pump [15].

\subsection{Amsterdam Rainproof}

The increasing population density of the city, in combination with the climate change phenomenon, makes the Amsterdam city vulnerable to the consequences of heavy rainfall. Citizens, institutions, companies and the municipality have to find an innovative way to deal with natural rain water. Amsterdam Rainproof project is a platform that activates and stimulates different stakeholders to improve water management. The main goal of this project is to collect water out of the rain and make better use of it, creating a sustainable rainproof platform [16].

\subsection{Vehicle2Grid}

Numerous multinational partners are cooperating in "Vehicle2Grid" pilot project including Alliander, Mitsubishi Motors Corporation, Cofely, ABB, Amsterdam Smart City, Amsterdam University of Applied Sciences and the borough of Nieuw-West. The cooperating smart project partners will provide support for three years, to tackle the various technical, economic, social and environmental impediments. This project will help move forward the large-scale implementation of electric vehicles, and the energetic independence of households. Inhabitants will be able to use the battery in their electric car to store the locally produced energy. Residents will be able to decide how to put the locally produced energy to use. The energy can be transferred to the energy grid, stored in the battery of an electric car, to be used at some later time to drive the car or run household appliances [17].

\subsection{Energetic Zuidoost}

Energetic Zuidoost project is part of the European Union's "TRANSFORM" program. Energetic Zuidoost project connects to reduce $\mathrm{CO}_{2}$-emissions in the area between the University of Amsterdam AMC Medical Centre and Amsterdam 
Arena. In the Zuidoost area, big steps can be taken to conserve and produce energy. The specific public space also presents an opportunity to broadcast the smart message to a substantial audience, considering a large number of daily commuters, employees and shoppers crisscrossing the area. Empty offices, the data-centres, plenty of hospitals and many flat-roofed buildings in the vicinity of can be developed into a proper 'energy factory,' rather energy producing landscape [18]. This is one of the best example for energy efficiency method.

\subsection{Smart lighting}

Smart lighting (as shown in Figure 3), can be adjusted for a range of circumstances via remote sensors, will improve security and save energy. For example, lighting can be adjusted according to the weather, coloured lighting can control the flow of the traffic and pedestrians. Movement sensors can also be used to register if the lighting needs to be brighter. Saved energy can then be used for other functions, such as powering the Wi-Fi network or measuring air quality [19]. Philips, Cisco, and Alliander, a Dutch utility firm, are teaming up for a smart lighting project in Amsterdam. The urban has promoted the use of energy-saving lamps in the city's domestic sector. The aim is to encourage the use of energy-saving lamps to reduce the overall electricity demand of the city, thus, considerably reducing energy costs for the residents and the substitution for energy-consuming bulbs [20].

From the perspective of becoming a smart sustainable city, Amsterdam is focusing on the challenge of saving energy to reduce $\mathrm{CO}_{2}$ emissions. To carry out this, Amsterdam Smart City, during its years, introduced and tested a vast number of energy-saving projects, which were divided into four areas (1) sustainable public space (2) sustainable mobility (3) sustainable living and (4) sustainable working, as described in Figure 4 [21]. We know that a city is nothing without its residents and visitors. In the metropolitan city area of Amsterdam, the total population is $2,289,762$, of which $58 \%$ people are using bicycles as a part of the sustainable concept. Besides, there are 40 parks and 216 trams for smart mobility. Smart School is a project where children in primary schools learn about saving energy while their school competes with other schools in energy efficiency. The 'Climate Street' is another public space project where a city street works as an incubator and testing place for new climate-friendly innovations and experiments. According to Alderperson for Sustainability Abdeluheb Choho, in (2014), the City of Amsterdam published its ambitious sustainability agenda delineating an action plan, of which a significant part was focused on creating a "circular city". In a "circular city," everything that one wants to achieve will come together with (1) less pollution (2) less waste and (3) buildings that produce their own energy" [22].

These are some of the smart projects, which were described in a nutshell in the text above; apart from these, Amsterdam Smart Citizens Lab, City distribution: Cargohopper, Hydrogen vehicle H2A, Koplopers D-020, MX3D Bridge Project, Amsterdam, Sloten Windmill, smart parking, Amsterdam Free Wi-Fi and geWoonboot, sustainable houseboat venue for meetings and training courses are a few among others (as depicted in Figure 5). These projects are focussed on designing and developing urban mobility solutions, especially car sharing, 


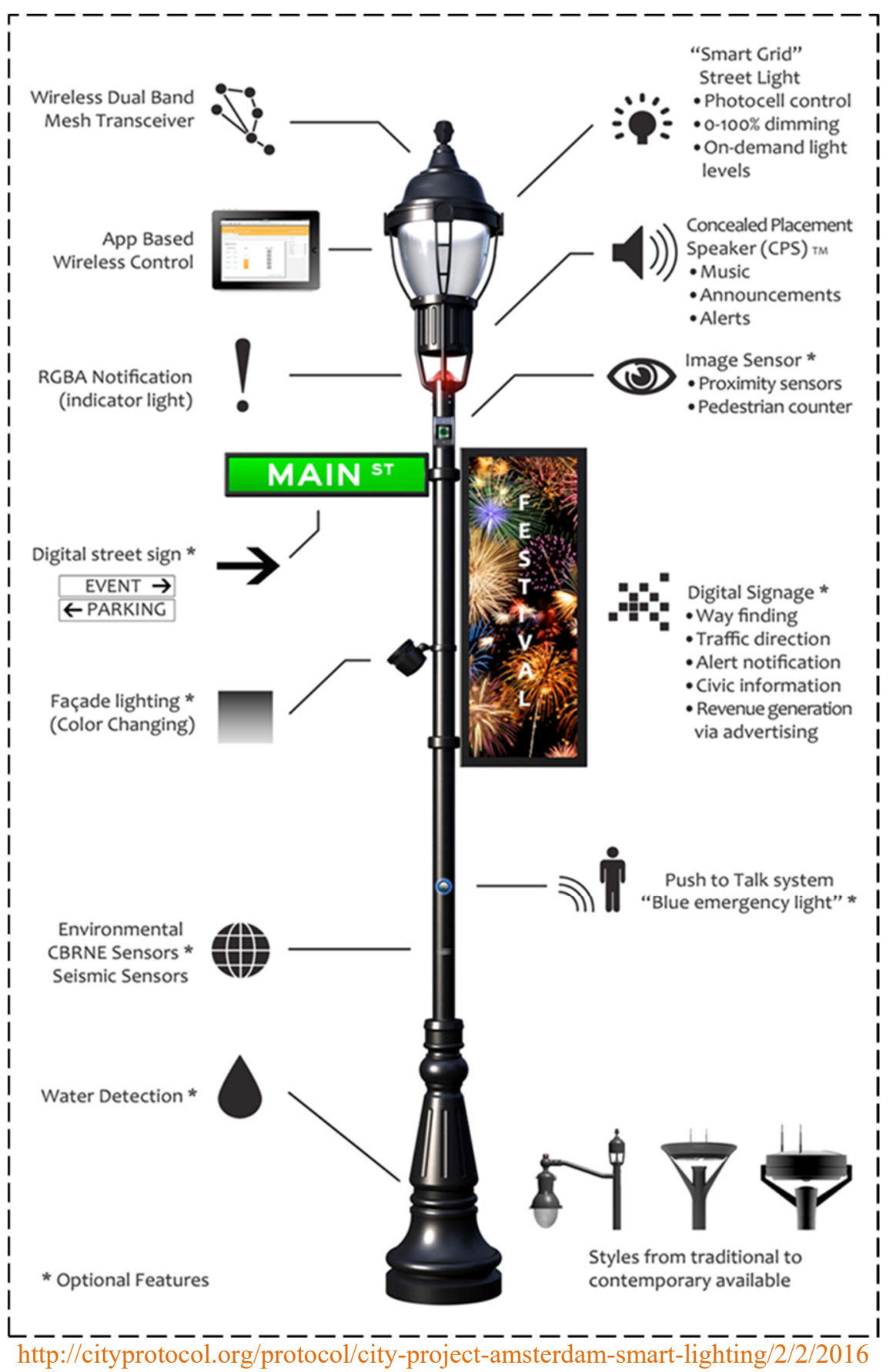

Figure 3: City Project-Amsterdam smart lighting. 


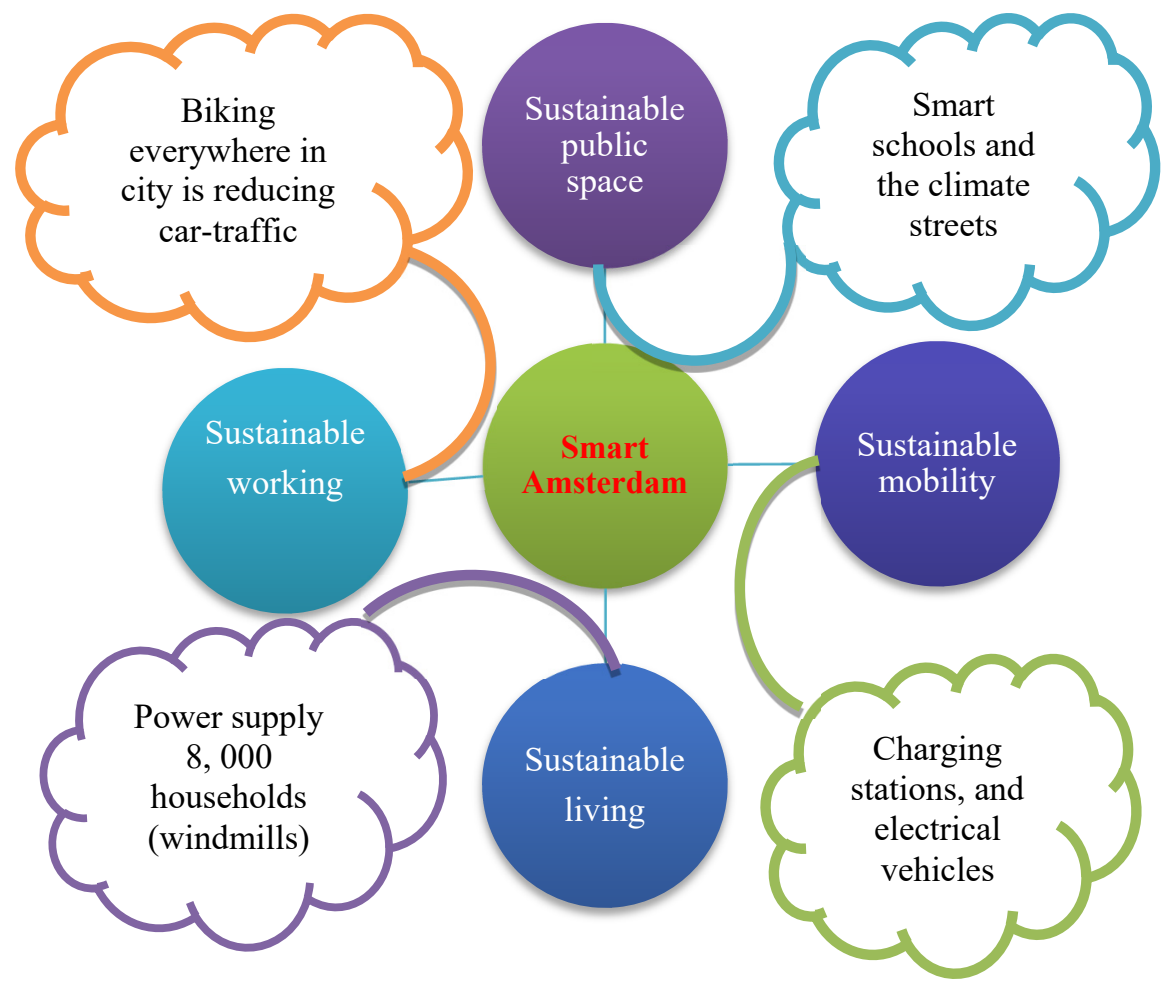

Figure 4: Energy savings projects.

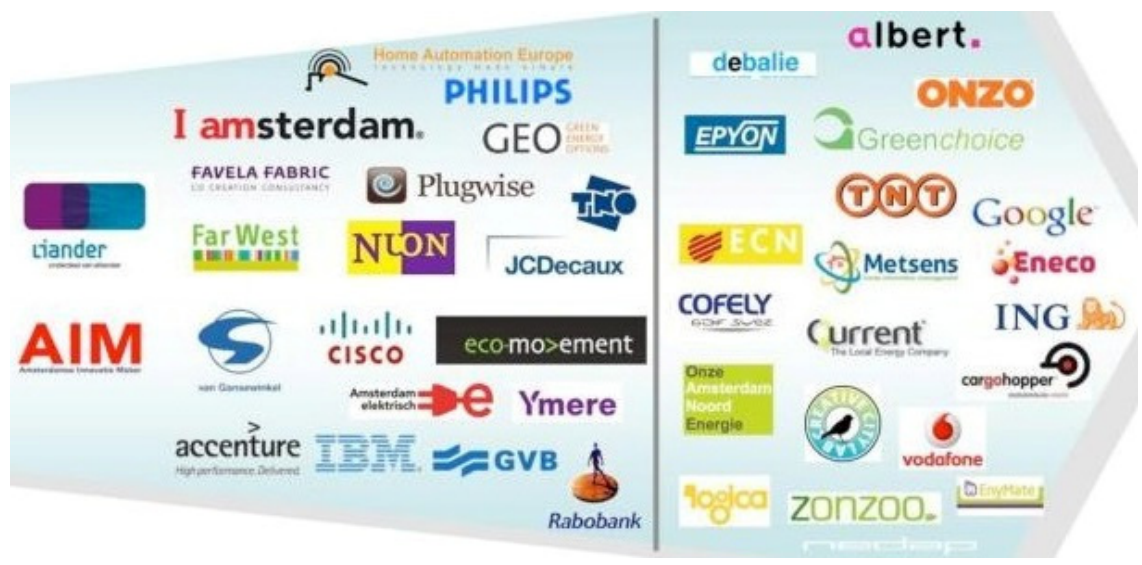

Figure 5: Collaborative smart projects partners. 
bicycling, pedestrians, and trams - which will reduce the traffic through online reservations, smart parking, and healthy journeys. These solutions will ultimately bring down the carbon footprint of the city. A large number of Internet of Things like GIS, GPS, and remote sensing are becoming popular in smart mobility for best travel routing, influencing travel choices. RFID and IP cameras are mounted in all public places in which commuters enjoy better security. Regarding public utilities like water, air, and power, the IoT technologies are deploying with these physical things to enhance efficient utilisation while in different modes of the sources-transmission-destination. Smart grid, smart (LED/saving) lighting, smart meters, electric vehicles, charging terminals, energy advice and ZigBee technologies will help prevent losses and control the leakages. The most interesting part is that all the billing and payment can be through smart mobile apps. Rainwater harvesting is also one of the sustainable smart city projects. In the city web portal, all the amenities including hospitals, education, entrainment, tourism, hotel services and transportation will be available. All these smart projects are working with a holistic approach to bring global sustainable future.

\section{References}

[1] Palla, G., Derényi, I., Farkas, I., \& Vicsek, T, Uncovering the overlapping community structure of complex networks in nature and society, Nature: 435(7043), 814-818, 2005.

[2] Zhang, S., Wang, R. S., \& Zhang, X. S., Identification of overlapping community structure in complex networks using fuzzy c-means clustering, Physica A: Statistical Mechanics and its Applications, 374(1), 483-490, 2007.

[3] Twidell, J., \& Weir, T, Renewable Energy Resources, Routledge, 2015.

[4] Finkbeiner, M., Schau, E. M., Lehmann, A., \& Traverso, M, Towards life cycle sustainability assessment. Sustainability: 2(10), 3309-3322, 2010.

[5] Werbach A., Strategy for Sustainability: A Business Manifesto, Harvard Business, Boston, MA, 2009.

[6] Nezhad, M. B., An empirical study on the contribution of lean practices to sustainable manufacturing: the role of lean culture as moderator, 2011.

[7] What is a smart sustainable city? URL link accessed dated on 3/12/2015, https://itunews.itu.int/en/5215-What-is-a-smart-sustainable-city.note.aspx

[8] Zanella, A., Bui, N., Castellani, A., Vangelista, L., \& Zorzi, M., Internet of Things for Smart Cities. Internet of Things Journal, IEEE, 1(1), 22-32, 2014.

[9] Haughton, G., \& Hunter, C., Sustainable cities. Routledge, 2004.

[10] Amsterdam, NL, Savannah Hines-Elzinga, URL link accessed on 3/10/2015, http://depts.washington.edu/open2100/Resources/1_OpenSpace Systems/Open_Space_Systems/Amsterdam.pdf

[11] Kavaratzis, M., \& Ashworth, G. J., Partners in coffeeshops, canals and commerce: Marketing the City of Amsterdam. Cities, 24(1), 16-25, 2007.

[12] Capello, R., Nijkamp, P., \& Pepping, G., Sustainable cities and energy policies. Springer Science \& Business Media, 1999. 
[13] Almere Smart Society, http://amsterdamsmartcity.com/ projects/detail/id /30/slug/almere-smart-society

[14] 3D Print Canal House, URL link accessed dated on 3/1/2015 from http:// amsterdamsmartcity.com/projects/detail/id/79/slug/3d-print-canal-house

[15] City-zen-Sustainable District, Heating, http://amsterdamsmartcity.com /projects/detail/id/86/slug/city-zen-sustainable-district-heating

[16] Amsterdam Rainproof, http://amsterdamsmartcity.com/ projects/detail /id/103/slug/amsterdam-rainproof

[17] Vehicle2Grid, http://amsterdamsmartcity.com/projects/detail/id/72/slug/ vehicle2 grid (accessed on 2/3/2016).

[18] Energetic Zuidoost, URL Link accessed dated on 3/1/2015 from http:// amsterdamsmartcity.com/projects/detail/id/49/slug/energetic-zuidoost

[19] Smart Light, Universal Resource Locator accessed dated on 13/11/2015 from http://amsterdamsmartcity.com/projects/detail/id/93/slug/smart-light

[20] Nijkamp, P., \& Perrels, A., Sustainable Cities in Europe, Routledge, 2014.

[21] Amsterdam: Smart City, http://www.dac.dk/en/dac-cities/sustainable-cities /all-cases/energy/amsterdam-smart-city/

[22] How Amsterdam goes circular, June 18, 2015/in News /by Circle economy, http:/www.circle-economy.com/news/how-amsterdam-goes-circular/

[23] Emas, R., The Concept of Sustainable Development: Definition and Defining Principles. Florida International University, 2015. 